OPEN ACCESS

Edited by:

Ansgar Thiel,

University of Tübingen, Germany

Reviewed by:

Dominic Malcolm,

Loughborough University,

United Kingdom

Cristiana Conti,

University of Studies G. d'Annunzio

Chieti and Pescara, Italy

*Correspondence:

Li Peng

804455169@qq.com

Specialty section:

This article was submitted to Movement Science and Sport

Psychology,

a section of the journal

Frontiers in Psychology

Received: 17 April 2021

Accepted: 14 June 2021

Published: 07 July 2021

Citation:

Liu H, Huang L, Yang Z, Li H, Wang Z and Peng $L$ (2021) Fear of

Movement/(Re)/njury: An Update to

Descriptive Review of the Related Measures. Front. Psychol. 12:696762.

doi: 10.3389/fpsyg.2021.696762

\section{Fear of Movement/(Re)Injury: An Update to Descriptive Review of the Related Measures}

\author{
Haowei Liu ${ }^{1}$, Li Huang ${ }^{1}$, Zongqian Yang ${ }^{1}$, Hansen Li $^{1}$, Zhenhuan Wang ${ }^{1}$ and Li Peng ${ }^{1,2 *}$ \\ ${ }^{1}$ College of Physical Education, Southwest University, Chongqing, China, ${ }^{2}$ Key Lab of Physical Fitness Evaluation and Motor \\ Function Monitoring, Southwest University, Chongqing, China
}

The prevalence of fear of movement (kinesiophobia) in persistent pain ranges from 50 to $70 \%$, and it may hinder the subsequent rehabilitation interventions. Therefore, the evaluation of fear of movement/(re)injury plays a crucial role in making clinical treatment decisions conducive to the promotion of rehabilitation and prognosis. In the decisionmaking process of pain treatment, the assessment of fear of movement/(re)injury is mainly completed by scale/questionnaire. Scale/questionnaire is the most widely used instrument for measuring fear of movement/(re)injury in the decision-making process of pain treatment. At present, the most commonly used scale/questionnaire are the Tampa Scale for Kinesiophobia (TSK), the Fear-Avoidance Beliefs Questionnaire (FABQ), the Kinesiophobia Causes Scale (KCS), the Athlete Fear-Avoidance Questionnaire (AFAQ), and the Fear-Avoidance Components Scale (FACS). In order to provide necessary tools and references for related research and rehabilitation treatment, this descriptive review is designed as an introduction to the background and content, score system, available language versions, variants of the original questionnaire, and psychometric properties of these scales/questionnaries.

Keywords: fear of movement/(re)injury, kinesiophobia, scales, questionnaires, scoring system

\section{INTRODUCTION}

In the past several decades, the relation between fear and pain has been described with various constructs. Fear of movement/(re)injury, pain-related fear, fear-avoidance beliefs, and kinesiophobia are the most commonly used constructs (Lundberg et al., 2011). In the 1980s, Lethem et al. (1983) developed the fear-avoidance model (FAM) to explain why some injuries transform from acute to chronic while others heal in normal time frames. In 1995, Vlaeyen et al. (1995) expanded the FAM into the cognitive-behavioral model of fear of movement/(re)injury. In that model, fear of movement/(re)injury was considered an important factor for disability, disuse syndrome, and depression in patients with musculoskeletal pain. If the patients misinterpret the pain and magnify the condition, in that case, they are likely to enter a maladaptive cycle of where fear of pain occurs, which leads to avoidance behavior and fear of movement/(re)injury. During the development of FAM, Kori (1990) proposed the concept of kinesiophobia that was defined for a patient who has "an excessive, irrational, and debilitating fear of physical movement and activity resulting from a feeling of vulnerability to painful injury or reinjury." The prevalence of kinesiophobia in persistent pain ranges from 50 to $70 \%$ (Luque-Suarez et al., 2019). A considerable number of longitudinal studies have found that a high level of kinesophobia at baseline can be used 
to predict the decreased quality of life, increased pain, and disability (Wong et al., 2015; Helminen et al., 2016; Maaike et al., 2017). Initially, the concept of "fear of movement/(re)injury" was applied to patients with chronic musculoskeletal pain (Vlaeyen et al., 1995). However, with the continuous exploration of researchers worldwide, research on other consequences accompanied by fear of movement/(re)injury gradually increased. In the clinical setting, fear of movement/(re)injury is an essential factor affecting the surgery (Doménech et al., 2014) and prognosis of physical therapy (Verwoerd et al., 2015), and it also can hinder the subsequent recovery of physical activity (Boutevillain et al., 2017). Assessing the fear of movement/(re)injury of the patients is helpful for researchers to explore the mechanism of chronic musculoskeletal pain more deeply and is useful for clinicians to make better clinical decisions.

Extensive research has shown that fear of movement/(re)injury is usually assessed with scales/questionnaires. The Tampa Scale for Kinesiophobia (TSK) (Miller et al., 1991) and the Fear-Avoidance Beliefs Questionnaire (FABQ) (Waddell et al., 1993) were designed in the early years. Some new measures like the Kinesiophobia Causes Scale (KCS) (Knapik et al., 2011), Athlete Fear-avoidance Questionnaire (AFAQ) (Dover and Amar, 2015), and FearAvoidance Components Scale (FACS) (Neblett et al., 2016) have been developed in recent years. Thus, renewing the information of these instruments is necessary for researchers and clinicians. The purpose of this article is to provide a descriptive review of each measure regarding the background and content, score system, available language versions, variants of the original questionnaire, and psychometric properties, which can offer the basis of scale selection and application reference for the research and clinical treatment of fear of movement/(re)injury.

\section{METHODOLOGY}

A search procedure, which involved searching electronic databases such as PubMed (https://pubmed.ncbi.nlm.nih.gov/), Web of Science (http://isiknowledge.com/), and Google Scholar (https://scholar.google.com/), was developed. The databases were searched from 1980 to 2021. Searches were carried out for the terms "kinesiophobia," "fear of movement/(re)injury," "scales," "questionnaires," "sports," and "fear-avoidance." All references were downloaded into the Zotero (version 5.0.96.2), which facilitated the large number of publications obtained. The aim of this review was to ensure that all the essential published papers were identified; nevertheless, some may have been missed out from the present review.

\section{THE TAMPA SCALE FOR KINESIOPHOBIA}

\section{Background and Content}

Miller et al. (1991) designed the TSK in 1991, but it was not published until 1995 (Acar et al., 2016). The TSK is one of the most well-known instruments for measuring fear of movement/(re)injury. Different models were proposed based on exploratory factor analysis (EFA) and confirmatory factor analysis (CFA): the generally accepted 2-factor model labeled somatic focus (TSK-SF; beliefs in underlying and serious medical problems) and activity avoidance (TSK-AA; beliefs that activity may result in [re]injury or increased pain) (Roelofs et al., 2004). Item response on a 5-point Likert scale range from 0 (strongly agree) to 4 (strongly disagree), including statements such as "I'm afraid that I might injure myself if I exercise (item 1)" and "If I were to try to overcome it, my pain would increase (item 2)."

\section{Score System}

The original TSK includes 17 items, among which 4 items (i.e., items $4,8,12$, and 16) are reverse-scored. The test's total score is the sum of the points marked by the patient, ranging from 17 to 68 . The higher the score, the higher the fear of movement/(re)injury of the patient. If the score is $>37$, the patient is considered to suffer from kinesiophobia.

\section{Available Language Versions}

As far as we know, it has been translated into Italian (Monticone et al., 2010), Japanese (Huang et al., 2019), Swedish (Larsson et al., 2014), Turkish (Acar et al., 2016), Dutch (Visscher et al., 2010), Chinese (Cai et al., 2019), Spanish (Aguiar et al., 2017), and Norwegian (Haugen et al., 2008).

\section{Variants of the Original Questionnaire}

Except low back pain, for which it was originally applied, the TSK was adapted for ACL injuries (Luc-Harkey et al., 2018; Huang et al., 2019), heart failure and pulmonary arterial hypertension (Acar et al., 2016), and temporomandibular disorders (GarrigósPedrón et al., 2018). The shortened versions of the TSK are TSK13 (Jørgensen et al., 2015), TSK-12 (Visscher et al., 2010), TSK-11 (Kikuchi et al., 2015; Goldberg et al., 2018), and TSK-4 (Gregg et al., 2015), among which TSK-11 is the most widely used.

\section{Psychometric Properties}

The Cronbach's $\alpha$ of each version of the TSK scale is generally between 0.7 and 0.92 , and the test-retest reliability is generally above 0.8 (Swinkels-Meewisse et al., 2003; Woby et al., 2005; Huang et al., 2019). Moderate correlation coefficients supported the construct validity with pain-related fear, pain catastrophizing, and disability in patients with chronic low back pain. Correlation coefficients supported a moderate predictive validity with performance on physical performance tests in patients with chronic low back pain. Concurrent validity is moderate, supported by Pearson's rho between TSK and FABQ in patients with acute low back pain, ranging from $r=0.33$ to $0.59(P<0.01$; Swinkels-Meewisse et al., 2003).

\section{FEAR-AVOIDANCE BELIEFS QUESTIONNAIRE}

\section{Background and Content}

The FABQ is a patient-reported questionnaire specially designed to measure fear-avoidance beliefs of patients about physical activity and work. It was developed by Waddell and published in 1993 (Waddell et al., 1993). The FABQ is a questionnaire based on the FAM, which was created to explain why some patients 
with acute painful conditions can recover while others develop chronic pain from such conditions (Lethem et al., 1983; Fritz and George, 2002). The FABQ total (FABQ-T) includes two subscales, the work subscale (FABQ-W) and the physical activity subscale (FABQ-PA). The form of answer is a standardized option (7point Likert fields), and each question is scored ranging from "completely disagree" (0) to "completely agree" (6). CFA showed that item 1 had low communality and had inconsistent factor loading while items 13,14 , and 16 were redundant (Waddell et al., 1993).

\section{Score System}

There are 16 items within the FABQ (maximum score of 66); FABQ-W with 7 questions (maximum score of 42 ) and FABQPA with 4 questions (maximum score of 24). Users should note that items 1, 8, 13, 14, and 16 are not scored (Table 1).

\section{Available Language Versions}

So far, in terms of the literature that we can be searched, the FABQ has been translated into Chinese (Pei et al., 2010), German (Pfingsten, 2004), Italian (Meroni et al., 2014), Brazilian (Abreu et al., 2008), Greek (Georgoudis et al., 2007), Thai (Wiangkham et al., 2020), Finnish (Pfingsten, 2016), and Hausa (Brox, 2019) d.

\section{Variants of the Original Questionnaire}

The FABQ has been adapted to assess fear-avoidance beliefs of patients in multiple areas, including low back pain (Fujii et al., 2013), chronic headache (Nash et al., 2006), fibromyalgia (Roelofs et al., 2004), neck pain (Lee et al., 2006), knee pain (Ross, 2010), shoulder pain (Mintken et al., 2010), osteoarthritis (Heuts et al., 2004), and even extended to burning pain (Sgroi et al., 2005) and complex regional pain syndrome type I (Jong et al., 2005).

\section{Psychometric Properties}

Most studies have verified the excellent reliability of the FABQ. A study showed that the test-retest reliability of FABQ-T, FABQ-W, and FABQ-PA are 0.97, $0.72 \sim 0.90$, and $0.80 \sim 0.91$, respectively (Williamson, 2006). Abreu et al. (2008) validated the Portuguese version of the FABQ the reliability of patients with low back pain, which showed that FABQ-P (ICC $=0.84$, Cronbach's $\alpha=0.80$ ) and FABQ-W (ICC $=0.91$, Cronbach's $\alpha=0.90)$. The correlation coefficients of FABQ-T, FABQ-W, and FABQ-PA with Roland and Morris Disability Questionnaire (RMDQ) are 0.52, 0.63, and 0.51 , respectively (Williamson, 2006). The correlation between TSK and FABQ-W and FABQ-PA was 0.33 and 0.39 (SwinkelsMeewisse et al., 2003). These pieces of evidence mentioned above

TABLE 1 | The items, total possible points, and high score from the fear-avoidance beliefs questionnaire (FABQ) and its subscale.

\begin{tabular}{llll}
\hline Scale Questions included & $\begin{array}{c}\text { Total } \\
\text { possible } \\
\text { points }\end{array}$ & High score \\
&
\end{tabular}

\begin{tabular}{lccc}
\hline FABQ-T & $2-7,9-12,15$ & 66 & None \\
FABQ-W & $6,7,9-12,15$ & 42 & $>34$ Fritz and George, 2002 \\
FABQ-PA & $2-5$ & 24 & $>15$ Crombez et al., 1999
\end{tabular}

supported that FABQ has good criterion validity. However, a study reported that the structural validity of FABQ was relatively low and that there was little evidence about the responsiveness before and after treatment (Lundberg et al., 2011).

\section{THE KINESIOPHOBIA CAUSES SCALE}

\section{Background and Content}

The KCS is a relatively new patient-reported outcome measure used to identify the biological and psychological causes of kinesiophobia in people (Knapik et al., 2011).

\section{Score System}

This scale is composed of 20 closed questions. The domain score is the mean of the total factors that make up the domain, while the overall index of kinesiophobia (KCS) is the mean of two domains. According to Knapik's assumption, the total KCS score will range from 0 to 100 and can be interpreted as a percent of kinesiophobic behavior-a higher score indicating higher fear of movement (Knapik et al., 2011). The calculations of the biological domain, psychological domain, and total KCS score are performed as $(\mathrm{A}+$ $\mathrm{B}+\mathrm{C}+\mathrm{D}) / 4,(\mathrm{E}+\mathrm{F}+\mathrm{G}+\mathrm{H}) / 4$, and (Biological Domain + Psychological Domain)/2, respectively (Table 2).

\section{Available Language Versions}

Currently, as far as the literature can be searched, English version (Knapik et al., 2011), Polish version (Brdak et al., 2015), Turkish version (Çayir et al., 2020), and Chinese version (Zhu et al., 2020) are available.

\section{Variants of the Original Questionnaire}

No other variants are available.

\section{Psychometric Properties}

The KCS was characterized with good internal consistency in a few studies. Saulicz et al. (2016) used the KCS to evaluate 105 women of perimenopausal age and verified that KCS had good internal consistency. Cronbach's $\alpha$ of the biological and psychological domain subscale were 0.79 and 0.77 , respectively.

TABLE 2 | The domain, dimensions, and calculation of the kinesiophobia causes scale (KCS).

\begin{tabular}{|c|c|c|}
\hline Domain & Dimension & Calculations \\
\hline \multirow{4}{*}{$\begin{array}{l}\text { Biological } \\
\text { domain }\end{array}$} & A. Morphologic (items 1-2) & $A=$ items $(1+2) / 2$ \\
\hline & $\begin{array}{l}\text { B. Individual need for } \\
\text { stimulation (items 3-5) }\end{array}$ & $\mathrm{B}=$ items $(3+4+5) / 3$ \\
\hline & $\begin{array}{l}\text { C. Energetic substrates (items } \\
6-9 \text { ) }\end{array}$ & $\mathrm{C}=$ items $(6+7+8+9) / 4$ \\
\hline & $\begin{array}{l}\text { D. Power of biological drives } \\
\text { (items 10-11) }\end{array}$ & $\mathrm{D}=$ items $(10+11) / 2$ \\
\hline \multirow[t]{4}{*}{$\begin{array}{l}\text { Psychological } \\
\text { domain }\end{array}$} & $\begin{array}{l}\text { E. Self-Acceptance } \\
\text { (items 12-14) }\end{array}$ & $\mathrm{E}=$ items $(12+13+14) / 3$ \\
\hline & $\begin{array}{l}\text { F. Self-Assessment of motor } \\
\text { predispositions }\end{array}$ & $F=$ items $(15+16) / 2$ \\
\hline & (items 15-16) & $\mathrm{G}=$ items $(17+18) / 2$ \\
\hline & $\begin{array}{l}\text { G. State of mind (items 17-18) } \\
\text { H. Susceptibility to social } \\
\text { influence (items 19-20) }\end{array}$ & $\mathrm{H}=$ items $(19+20) / 2$ \\
\hline
\end{tabular}


The Cronbach's $\alpha$ of KCS total scale, biological domain, and psychological domain in the Turkish version are $0.86,0.91$, and 0.80, respectively (Çayir et al., 2020).

\section{ATHLETE FEAR-AVOIDANCE QUESTIONNAIRE}

\section{Background and Content}

In 2015, Dover developed the AFAQ, a sport-specific scale, to identify the high levels of fear-avoidance in athletes (Dover and Amar, 2015). Therapists and trainers can use it as a tool to address this psychological barrier early in rehabilitation and potentially reduce the time until they return to the game. As it is specially developed for athletes, the scale uses relevant terms that athletes can understand, including the expressions of "I will never be able to play as I did before the injury (item 1)" and "I believe that my current injury has jeopardized my future athletic abilities (item 5)." The AFAQ contains 10 items related to sports psychology, sports injury, and sports experience. The scale is measured on a 5-point Likert scale ranging from 1 (Not at all) to 5 (completely agree).

\section{Score System}

The total score ranged from 10 to 50, where the higher the score, the more fear-avoidance the athletes possess (Dover and Amar, 2015).

\section{Available Language Versions}

To our knowledge, the scale is available in three languages, English (Dover and Amar, 2015), Japanese (Fukano et al., 2019), and Portuguese (Leitão, 2019).

\section{Variants of the Original Questionnaire}

O'Keeffe et al. (2020) developed a modified AFAQ (mAFAQ) to make it a screening tool for fear-avoidance of athletes. Unlike the original version, the sentence "if I am injured" is added to each of the 10 statements to predict the degree of injury-related fear-avoidance that an athlete may occur after injury. The study showed that mAFAQ is a valid and reliable screening tool in predicting injury (O'Keeffe et al., 2020).

\section{Psychometric Properties}

The internal consistency of AFAQ was very high (Cronbach's $\alpha=0.805)$, and it was significantly correlated with FABQ and other assessment tools $(r=0.352, P<001)$, which verified its concurrent validity (Dover and Amar, 2015). The results of the Portuguese version showed that the test-retest reliability of AFAQ is excellent (ICC $=0.969)$ (Leitão, 2019).

\section{FEAR-AVOIDANCE COMPONENTS SCALE}

\section{Background and Content}

The FACS is a newly developed scale developed by Neblett et al. (2016) in 2016, which combines the essential components of several well-studied scales (TSK, FABQ, Pain Anxiety Symptom Scale, and Pain Catastrophizing Scale), to evaluate the psychological characteristics of fear-avoidance in patients with painful medical conditions comprehensively. The items of the FACS are trying to correct the deficiencies of the above scales based on the latest fear-avoidance model. There were 20 items in the FACS, and each item was scored on a 6-point Likert scale ranging from 0 (completely disagree) to 5 (completely agree). The total score was $0-100$, indicating subclinical (0-20), mild (21$40)$, moderate (41-60), severe (61-80), and extreme (81-100).

\section{Score System}

The final score is the sum of each item. Higher scores are intended to indicate higher levels of fear-avoidance (Neblett et al., 2016).

\section{Available Language Versions}

So far, there are four language versions available, including English (Neblett et al., 2016), Serbian (Knezevic et al., 2018), Gujarati (Bid et al., 2020), and Spanish (Cuesta-Vargas et al., 2020).

\section{Variants of the Original Questionnaire}

No other variants are available.

\section{Psychometric Properties}

Tested by Neblett et al. (2016), the English version of FACS has good internal consistency (Chronbach's $\alpha=0.92$ ) and high test-retest reliability $(r=0.90 \sim 0.94, P<0.01)$. In 2018, the Serbian version of FACS introduced by Knezevic et al. (2018) studied 322 patients with chronic musculoskeletal pain. In 2020, Cuesta-Vargas et al. (2020) selected 330 patients with chronic musculoskeletal pain and verified the adaptability of the Spanish version (FACS-Sp). Their Cronbach's $\alpha$ were 0.90 and 0.88 , respectively. The convergent validity is supported by Pearson's correlation with Central Sensitization Inventory $(r=0.414)$.

\section{DISCUSSION}

The scales and questionnaires determine the severity of fear of movement/(re)injury in patients with different medical conditions. By presenting these five scales, it can be seen that the assessments of fear of movement/(re)injury tend to be more rigorously subdivided, such as special populations, causes, and components, and are becoming more comprehensive. From a perspective of use, the citations from high to low were FABQ (3268), TSK (493), KCS (61), AFAQ (29), and FACS (26). It is noted that researchers or clinicians need to be cautious in selecting the last three tables, due to which they were not wellstudied as the former two. The TSK is the earliest instrument to measure fear of movement/(re)injury, and it has many language versions and a wide range of applications. A study showed that the TSK was sensitive in detecting clinical changes in subjects undergoing rehabilitation after lumbar fusion and chronic low back pain (Monticone et al., 2016). However, the validity of the TSK was low to moderate (Lundberg et al., 2011). Compared with the other shortened versions, the internal consistency of TSK-4 is insufficient (Archer et al., 2012). According to Japanese research on the TSK, the scale may not be the best tool for assessing psychological factors in patients with knee anterior 
ligament injury (Huang et al., 2019). Currently, most studies believed the FABQ seems to be the best available measure to measure "fear-avoidance beliefs." Still, a recent study questioned this, suggesting that the FABQ questionnaire is most likely related to expectations rather than fear (Aasdahl et al., 2020). The FABQ can discriminate between patients with cervical radiculopathy and healthy subjects (Dedering and Börjesson, 2013). Compared with the TSK, a recognized cutoff score of the FABQ is still not available (Wertli et al., 2014). In addition, the construct validity of FABQ is relatively low, and there is little evidence of responsiveness before and after treatment (Lundberg et al., 2011). The KCS tries to identify and quantify the causes of kinesiophobia in patients from two domains: biology and psychology. Nevertheless, the research on KCS is dominated by Polish researchers, and the cross-cultural adaptation and validation of other versions need to be further studied. Moreover, the KCS scoring system is a little bit complicated and requires special attention when using it. The AFAQ is a sport-specific questionnaire used to evaluate the thoughts of athletes regarding injury and return to the competitions. However, there are few studies on the reliability and validity of AFAQ. Whether the questionnaire is still reliable in other languages/cultural backgrounds needs more studies to verify. The FACS is based on a developed FAM to improve the disadvantage of the wellstudied measures. It has good psychometric characteristics and has five grades of severity range for clinical interpretation. It seems the most comprehensive scale so far. The application of FACS is still few, and its characteristics and limitations need to be further explored.

\section{CONCLUSION}

The present review has provided a general description of existing measures from 1991 (TSK) to 2016 (FACS). These scales/questionnaires mentioned above are useful tools for assessing the constructs related to fear of movement/(re)injury

\section{REFERENCES}

Aasdahl, L., Marchand, G. H., Gismervik, S. Ø., Myhre, K., Fimland, M. S., and Røe, C. (2020). The fear avoidance beliefs questionnaire (FABQ) does it really measure fear beliefs? Spine 45, 134-140. doi: 10.1097/BRS.0000000000003188

Abreu, A. M. D., Faria, C. D. C. D. M., Cardoso, S. M. V., and Teixeira-Salmela, L. F. (2008). The Brazilian version of the fear avoidance beliefs questionnaire. Cad Saude Publica 24, 615-623. doi: 10.1590/S0102-311X2008000300015

Acar, S., Savci, S., Keskinoglu, P., Akdeniz, B., and Sevinc, C. (2016). Tampa scale of kinesiophobia for heart turkish version study: cross-cultural adaptation, exploratory factor analysis, and reliability. J. Pain Res. 9, 445-451. doi: $10.2147 /$ JPR.S105766

Aguiar, A. D. S., Bataglion, C., Visscher, C. M., Grossi, D. B., and Chaves, T. C. (2017). Cross-cultural adaptation, reliability and construct validity of the tampa scale for kinesiophobia for temporomandibular disorders (TSK/TMDBr) into Brazilian Portuguese. J. Oral Rehabil. 44, 500-510. doi: 10.1111/joor. 12515

Archer, K. R., Phelps, K. D., Seebach, C. L., Song, Y., Iii, L. H. R., and Wegener, S. T. (2012). Comparative study of short forms of the tampa scale for kinesiophobia: fear of movement in a surgical spine population. Arch. Phys. Med. Rehabil. 93, 1460-1462. doi: 10.1016/j.apmr.2012.03.024 in several different types of studies. After comparison, it was found that no scale/questionnaire can evaluate all the characteristics of fear of movement/(re)injury. Still, the results of the measurements illustrate how much the different aspects of fear of movement/(re)injury limit the ability of the patient to perform the necessary life functions, thus giving an idea of how it affects the quality of life, pain, and disability. Considering that fear of movement/(re)injury has become a common factor of rehabilitation, using the scales presented allows clinicians to assess surgical/rehabilitation treatment results. Each questionnaire should be considered for its characteristics when using in research and clinical practice. If necessary, the combination of those scales can be considered. Therefore, with the help of adequately used fear of movement/(re)injury outcome measures, effective treatment methods can be selected and applied.

\section{AUTHOR CONTRIBUTIONS}

HLiu composed this study. LH designed the framework. ZY, $\mathrm{HLi}$, and ZW revised the manuscript. LP provided supervision throughout the research and made critical revisions to this study. All authors contributed to the article and approved the submitted version.

\section{FUNDING}

This work was supported by the Innovation Team Project of Southwest University (SWU1909105).

\section{SUPPLEMENTARY MATERIAL}

The Supplementary Material for this article can be found online at: https://www.frontiersin.org/articles/10.3389/fpsyg. 2021.696762/full\#supplementary-material
Bid, D., Neblett, R., Alagappan, T., Patel, C., Patel, K., Patel, R., et al. (2020). Cross-cultural adaptation, reliability, and validity of the Gujarati fearavoidance components scale. Physiother. J. Indian Assoc. Physiother. 14:98. doi: 10.4103/PJIAP.PJIAP_35_19

Boutevillain, L., Dupeyron, A., Rouch, C., Richard, E., and Coudeyre, E. (2017). Facilitators and barriers to physical activity in people with chronic low back pain: a qualitative study. PLOS ONE 12:e0179826. doi: 10.1371/journal.pone.0179826

Brdak, M., Utykański, H., and Utykańska, A. (2015). Socjodemograficzne Uwarunkowania Kinezjofobii u Osób ze Schorzeniami Układu SercowoNaczyniowego. Wroclawiu: Rozprawy Naukowe.

Brox, J. I. (2019). The fear avoidance beliefs questionnaire - the FABQ - for the benefit of another 70 million potential pain patients. Scand. J. Pain 19, 1-2. doi: 10.1515/sjpain-2018-2005

Cai, L., Liu, Y., Woby, S. R., Genoosha, N., Cui, M., and Guo, L. (2019). CrossCultural adaptation, reliability, and validity of the chinese version of the tampa scale for kinesiophobia-11 among patients who have undergone total knee arthroplasty. J. Arthroplasty 34, 1116-1121. doi: 10.1016/j.arth.2019.01.076

Çayir, M., Durutürk, N. A., and Tekindal, M. A. (2020). Kinezyofobi nedenleri ölçeği'nin türkçe uyarlamasinin geçerlik ve güvenirliği. J. Exerc. Ther. Rehabil. 7, 64-73. 
Crombez, G., Vlaeyen, J., Heuts, P., and Lysens, R. (1999). Pain-related fear is more disabling than pain itself: evidence on the role of pain-related fear in chronic back pain disability. Pain 80, 329-339. doi: 10.1016/S0304-3959(98)00229-2

Cuesta-Vargas, A. I., Neblett, R., Gatchel, R. J., and Roldán-Jiménez, C. (2020). Cross-Cultural adaptation and validity of the Spanish fear-avoidance components scale and clinical implications in primary care. BMC Family Pract. 21:44. doi: 10.1186/s12875-020-01116-x

Dedering, Å., and Börjesson, T. (2013). Assessing fear-avoidance beliefs in patients with cervical radiculopathy: assessing fear-avoidance in cervical radiculopathy. Physiother. Res. Int. 18, 193-202. doi: 10.1002/pri.1545

Doménech, J., Sanchis-Alfonso, V., and Espejo, B. (2014). Changes in catastrophizing and kinesiophobia are predictive of changes in disability and pain after treatment in patients with anterior knee pain. Knee Surg. Sports Traumatol. Arthrosc. 22, 2295-2300. doi: 10.1007/s00167-014-2968-7

Dover, G., and Amar, V. (2015). Development and validation of the athlete fear avoidance questionnaire. J. Athl. Train. 50, 634-642. doi: 10.4085/1062-6050-49.3.75

Fritz, J. M., and George, S. Z. (2002). Identifying psychosocial variables in patients with acute work-related low back pain: the importance of fear-avoidance beliefs. Phys. Ther. 82, 973-983. doi: 10.1093/ptj/82.10.973

Fujii, T., Matsudaira, K., and Oka, H. (2013). Factors associated with fearavoidance beliefs about low back pain. J. Orthop. Sci. 18, 909-915. doi: 10.1007/s00776-013-0448-4

Fukano, M., Mineta, S., Hoshiba, T., Hirose, T., and Fukubayashi, T. (2019). Development of a Japanese version of the athlete fear avoidance questionnaire (AFAQ-J) [in Japanese]. Jpn. J. Clin. Sports Med. 27, 145-148. doi: 10.1055/a-1065-1940

Garrigós-Pedrón, M., La Touche, R., Navarro-Desentre, P., Gracia-Naya, M., and Segura-Ortí, E. (2018). Effects of a physical therapy protocol in patients with chronic migraine and temporomandibular disorders: a randomized, single-blinded, clinical trial. J. Oral Facial Pain Headache 32, 137-150. doi: $10.11607 /$ ofph.1912

Georgoudis, G., Papathanasiou, G., Spiropoulos, P., and Katsoulakis, K. (2007). Cognitive assessment of musculoskeletal pain with a newly validated Greek version of the fear-avoidance beliefs questionnaire (FABQ). Euro. J. Pain 11, 341-351. doi: 10.1016/j.ejpain.2006.05.001

Goldberg, P., Zeppieri, G., Bialosky, J., Bocchino, C., van den Boogaard, J., Tillman, S., et al. (2018). Kinesiophobia and its association with health-related quality of life across injury locations. Arch. Phys. Med. Rehabil. 99, 43-48. doi: 10.1016/j.apmr.2017.06.023

Gregg, C. D., McIntosh, G., Hall, H., Watson, H., Williams, D., and Hoffman, C. W. (2015). The relationship between the tampa scale of kinesiophobia and low back pain rehabilitation outcomes-ScienceDirect. Spine J. 15, 2466-2471. doi: 10.1016/j.spinee.2015.08.018

Haugen, A. J., Grøvle, L., Keller, A., and Grotle, M. (2008). Cross-Cultural adaptation and validation of the Norwegian version of the tampa scale for kinesiophobia. Spine 33, 595-601. doi: 10.1097/BRS.0b013e31817c6c4b

Helminen, E.-E., Sinikallio, S. H., Valjakka, A. L., Väisänen-Rouvali, R. H., and Arokoski, J. P. (2016). Determinants of pain and functioning in knee osteoarthritis: a one-year prospective study. Clin. Rehabil. 30, 890-900. doi: 10.1177/0269215515619660

Heuts, P. H. T. G., Vlaeyen, J. W. S., Roelofs, J., Bie, R. A. D., Aretz, K., Weel, C. V., et al. (2004). Pain-related fear and daily functioning in patients with osteoarthritis. Pain 110, 228-235. doi: 10.1016/j.pain.2004. 03.035

Huang, H., Nagao, M., Arita, H., Shiozawa, J., Nishio, H., Kobayashi, Y., et al. (2019). Reproducibility, responsiveness and validation of the tampa scale for kinesiophobia in patients with ACL injuries. Health Qual. Life Outcomes 17, 1-8. doi: 10.1186/s12955-019-1217-7

Jong, J. R. D., Vlaeyen, J. W. S., Onghena, P., Cuypers, C., Hollander, M. D., and Ruijgrok, J. (2005). Reduction of pain-related fear in complex regional pain syndrome type I: the application of graded exposure in vivo. Pain 116, 264-275. doi: 10.1016/j.pain.2005.04.019

Jørgensen, M. B., Damsgård, E., Holtermann, A., Anke, A., Søgaard, K., and Røe, C. (2015). Properties of the tampa scale for kinesiophobia across workers with different pain experiences and cultural backgrounds: a rasch analysis. J. Appl. Measure. 16, 218-227.
Kikuchi, N., Matsudaira, K., Sawada, T., and Oka, H. (2015). Psychometric properties of the Japanese version of the tampa scale for kinesiophobia (TSK-J) in patients with whiplash neck injury pain and/or low back pain. J. Orthop. Sci. 20, 985-992. doi: 10.1007/s00776-015-0751-3

Knapik, A., Saulicz, E., and Gnat, R. (2011). Kinesiophobia-introducing a new diagnostic tool. J. Hum. Kinet. 28, 25-31. doi: 10.2478/v10078-011-0019-8

Knezevic, A., Neblett, R., Gatchel, R. J., Jeremic-Knezevic, M., Bugarski-Ignjatovic, V., Tomasevic-Todorovic, S., et al. (2018). Psychometric validation of the Serbian version of the fear avoidance component scale (FACS). PLoS ONE 13:e0204311. doi: 10.1371/journal.pone.0204311

Kori, S. (1990). Kinisophobia: a new view of chronic pain behavior. Pain Manage 35-43.

Larsson, C., Hansson, E. E., Sundquist, K., and Jakobsson, U. (2014). Psychometric properties of the tampa scale of kinesiophobia (TSK-11) among older people with chronic pain. Physiother. Theory Pract. 30, 421-428. doi: $10.3109 / 09593985.2013 .877546$

Lee, K.-C., Chiu, T. T., and Lam, T.-H. (2006). Psychometric properties of the fearavoidance beliefs questionnaire in patients with neck pain. Clin. Rehabil. 20, 909-920. doi: 10.1177/026921550506072186

Leitão, R. A. B. G. M. (2019). Cultural and Linguistic Adaptation of "Athletic Fear Avoidance Questionnaire.” Portuguese Version (PhD Thesis). Porto.

Lethem, J., Slade, P. D., Troup, J. D. G., and Bentley, G. (1983). Outline of a fear-avoidance model of exaggerated pain perception-I. Behav. Res. Ther. 21, 401-408. doi: 10.1016/0005-7967(83)90009-8

Luc-Harkey, B. A., Franz, J. R., Losina, E., and Pietrosimone, B. (2018). Association between kinesiophobia and walking gait characteristics in physically active individuals with anterior cruciate ligament reconstruction. Gait Posture 64, 220-225. doi: 10.1016/j.gaitpost.2018.06.029

Lundberg, M., Grimby-Ekman, A., Verbunt, J., and Simmonds, M. J. (2011). PainRelated fear: a critical review of the related measures. Pain Res. Treat. 2011, 1-26. doi: 10.1155/2011/494196

Luque-Suarez, A., Martinez-Calderon, J., and Falla, D. (2019). Role of kinesiophobia on pain, disability and quality of life in people suffering from chronic musculoskeletal pain: a systematic review. Br. J. Sports Med. 53, 554-559. doi: 10.1136/bjsports-2017-098673

Maaike, V., Luyckx, K., Oudenhove, L. V., Bogaerts, K., Diest, I. V., Bie, J. D., et al. (2017). Differentiating progress in a clinical group of fibromyalgia patients during and following a multicomponent treatment program. J. Psychosom. Res. 98, 47-54. doi: 10.1016/j.jpsychores.2017.05.004

Meroni, R., Piscitelli, D., Bonetti, F., Zambaldi, M., Guccione, A. A., and Pillastrini, P. (2014). Rasch analysis of the Italian version of fear avoidance beliefs questionnaire (FABQ-I). Disabil. Rehabil. 37, 151-157. doi: 10.3109/09638288.2014.909890

Miller, R. P., Kori, S. H., and Todd, D. D. (1991). The tampa scale. Clin. J. Pain 7:51. doi: 10.1097/00002508-199103000-00053

Mintken, P. E., Cleland, J. A., Whitman, J. M., and George, S. Z. (2010). Psychometric properties of the fear-avoidance beliefs questionnaire and tampa scale of kinesiophobia in patients with shoulder pain. Arch. Phys. Med. Rehabil. 91, 1128-1136. doi: 10.1016/j.apmr.2010.04.009

Monticone, M., Ambrosini, E., Rocca, B., Foti, C., and Ferrante, S. (2016). Responsiveness of the tampa scale of kinesiophobia in Italian subjects with chronic low back pain undergoing motor and cognitive rehabilitation. Euro. Spine J. 25, 2882-2888. doi: 10.1007/s00586-016-4682-2

Monticone, M., Giorgi, I., Baiardi, P., Barbieri, M., Rocca, B., and Bonezzi, C. (2010). Development of the Italian version of the tampa scale of kinesiophobia (TSK-I): cross-cultural adaptation, factor analysis, reliability, and validity. Spine 35, 1241-1246. doi: 10.1097/BRS.0b013e3181bfcbf6

Nash, J. M., Williams, D. M., Nicholson, R., and Trask, P. C. (2006). The contribution of pain-related anxiety to disability from headache. J. Behav. Med. 29, 61-67. doi: 10.1007/s10865-005-9033-4

Neblett, R., Mayer, T. G., Hartzell, M. M., Williams, M. J., and Gatchel, R. J. (2016). The fear-avoidance components scale (FACS): development and psychometric evaluation of a new measure of pain-related fear avoidance. Pain Pract. 16, 435-450. doi: 10.1111/papr.12333

O'Keeffe, S. N., Chéilleachair, N., and O'Connor, S. (2020). Fear avoidance following musculoskeletal injury in male adolescent gaelic footballers. J. Sport Rehabil. 29, 413-419. doi: 10.1123/jsr.2018-0258 
Pei, L., Xia, J., and Yan, J. (2010). Cross-Cultural adaptation, reliability and validity of the chinese version of the fear avoidance beliefs questionnaire. J. Int. Med. Res. 38, 1985-1996. doi: 10.1177/147323001003800612

Pfingsten, M. (2004). Angstvermeidungs-berzeugungen bei rückenschmerzen: gütekriterien und prognostische relevanz des FABQ. Der Schmerz 18, 17-27. doi: 10.1007/s00482-003-0244-8

Pfingsten, M. (2016). Finnish version of the fear-avoidance-beliefs questionnaire (FABQ) and the importance of validated questionnaires on FAB in clinical praxis and in research on low-back pain. Scand. J. Pain 10, 111-112. doi: 10.1016/j.sjpain.2015.11.002

Roelofs, J., Goubert, L., Peters, M. L., Vlaeyen, J. W. S., and Crombez, G. (2004). The tampa scale for kinesiophobia: further examination of psychometric properties in patients with chronic low back pain and fibromyalgia. Euro. J. Pain 8, 495-502. doi: 10.1016/j.ejpain.2003.11.016

Ross, M. D. (2010). The relationship between functional levels and fearavoidance beliefs following anterior cruciate ligament reconstruction. J. Orthop. Traumatol. 11, 237-243. doi: 10.1007/s10195-010-0118-7

Saulicz, M., Saulicz, E., Knapik, A., Linek, P., Rottermund, J., Myśliwiec, A., et al. (2016). Impact of physical activity and fitness on the level of kinesiophobia in women of perimenopausal age. Menopausal Rev. 2, 104-111. doi: $10.5114 / \mathrm{pm} .2016 .61193$

Sgroi, M. I., Willebrand, M., Ekselius, L., Gerdin, B., and Andersson, G. (2005). Fear-Avoidance in recovered burn patients: association with psychological and somatic symptoms. J. Health Psychol. 10, 491-502. doi: $10.1177 / 1359105305053410$

Swinkels-Meewisse, E. J. C. M., Swinkels, R. A. H. M., Verbeek, A. L. M., Vlaeyen, J. W. S., and Oostendorp, R. A. B. (2003). Psychometric properties of the Tampa Scale for kinesiophobia and the fear-avoidance beliefs questionnaire in acute low back pain. Man. Ther. 8, 29-36. doi: 10.1054/math.2002.0484

Verwoerd, A. J. H., Luijsterburg, P. A. J., Koes, B. W., el Barzouhi, A., and Verhagen, A. P. (2015). Does kinesiophobia modify the effects of physical therapy on outcomes in patients with sciatica in primary care? Subgroup analysis from a randomized controlled trial. Phys. Ther. 95, 1217-1223. doi: $10.2522 / \mathrm{ptj} .20140458$

Visscher, C. M., Ohrbach, R., Wijk, A. J. V., Wilkosz, M., and Naeije, M. (2010). The tampa scale for kinesiophobia for temporomandibular disorders (TSK-TMD). Pain 150, 492-500. doi: 10.1016/j.pain.2010.06.002

Vlaeyen, J. W. S., Kole-Snijders, A. M. J., Boeren, R. G. B., and van Eek, H. (1995). Fear of movement/(re)injury in chronic low back pain and its relation to behavioral performance: Pain 62, 363-372. doi: 10.1016/0304-3959(94)00279-N
Waddell, G., Mary, N., Iain, H., Douglas, S., and Main, C. (1993). A fearavoidance beliefs questionnaire (FABQ) and the role of fear-avoidance beliefs in chronic low back pain and disability. Pain 52, 157-168. doi: 10.1016/0304-3959(93)90127-B

Wertli, M. M., Rasmussen-Barr, E., Weiser, S., Bachmann, L. M., and Brunner, F. (2014). The role of fear avoidance beliefs as a prognostic factor for outcome in patients with nonspecific low back pain: a systematic review. Spine J. 14, 816-836.e4. doi: 10.1016/j.spinee.2013. 09.036

Wiangkham, T., Phungwattanakul, N., Tedsombun, P., Kongmee, I., Suwanmongkhon, W., and Chidnok, W. (2020). Translation, cross-cultural adaptation and psychometric evaluation of the Thai version of the fearavoidance beliefs questionnaire in patients with non-specific neck pain. Scand. J. Pain 1 doi: 10.1515/sjpain-2020-0116. [Epub ahead of print].

Williamson, E. (2006). Fear avoidance beliefs questionnaire (FABQ). Austra. J. Physiother. 52, 149. doi: 10.1016/S0004-9514(06)70052-6

Woby, S. R., Roach, N. K., Urmston, M., and Watson, P. J. (2005). Psychometric properties of the TSK-11: a shortened version of the tampa scale for kinesiophobia. Pain 117, 137-144. doi: 10.1016/j.pain.2005. 05.029

Wong, W. S., Chow, Y. F., Chen, P. P., Wong, S., and Fielding, R. (2015). A longitudinal analysis on pain treatment satisfaction among Chinese patients with chronic pain: predictors and association with medical adherence, disability, and quality of life. Qual. Life Res. 24, 2087-2097. doi: 10.1007/s11136-015-0955-1

Zhu, H., Zhang, D., Jin, K., and Chen, X. (2020). The reliability and validity of the chinese version of kinesiophobia causes scale. Chinese PLA J. Nurs. 37, 1-4. doi: 10.3969/j.issn.1008-9993.2020. 01.001

Conflict of Interest: The authors declare that the research was conducted in the absence of any commercial or financial relationships that could be construed as a potential conflict of interest.

Copyright (C) 2021 Liu, Huang, Yang, Li, Wang and Peng. This is an open-access article distributed under the terms of the Creative Commons Attribution License (CC $B Y)$. The use, distribution or reproduction in other forums is permitted, provided the original author(s) and the copyright owner(s) are credited and that the original publication in this journal is cited, in accordance with accepted academic practice. No use, distribution or reproduction is permitted which does not comply with these terms. 